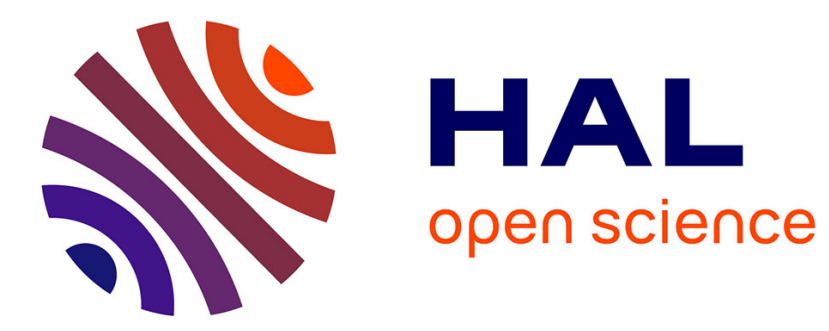

\title{
Microstructural design of functionally graded coatings composed of suspension plasma sprayed hydroxyapatite and bioactive glass
}

\author{
Andrea Cattini, Devis Bellucci, Antonella Sola, Lech Pawlowski, Valeria \\ Cannillo
}

\section{To cite this version:}

Andrea Cattini, Devis Bellucci, Antonella Sola, Lech Pawlowski, Valeria Cannillo. Microstructural design of functionally graded coatings composed of suspension plasma sprayed hydroxyapatite and bioactive glass. Journal of Biomedical Materials Research Part B: Applied Biomaterials, 2014, 102 (3), pp.551-560. 10.1002/jbm.b.33034 . hal-01103085

\section{HAL Id: hal-01103085 \\ https://hal.science/hal-01103085}

Submitted on 14 Jan 2015

HAL is a multi-disciplinary open access archive for the deposit and dissemination of scientific research documents, whether they are published or not. The documents may come from teaching and research institutions in France or abroad, or from public or private research centers.
L'archive ouverte pluridisciplinaire HAL, est destinée au dépôt et à la diffusion de documents scientifiques de niveau recherche, publiés ou non, émanant des établissements d'enseignement et de recherche français ou étrangers, des laboratoires publics ou privés. 


\title{
Microstructural design of functionally graded coatings composed of suspension plasma sprayed hydroxyapatite and bioactive glass
}

\author{
Andrea Cattini, ${ }^{1,2}$ Devis Bellucci, ${ }^{1}$ Antonella Sola, ${ }^{1}$ Lech Pawłowski, ${ }^{2}$ Valeria Cannillo \\ ${ }^{1}$ Department of Engineering “Enzo Ferrari," University of Modena and Reggio Emilia, Via Vignolese, 905 - 41125 Modena \\ (MO), Italy \\ ${ }^{2}$ SPCTS, UMR CNRS 7315, University of Limoges, F-87068 Limoges, France
}

Received 19 July 2013; accepted 28 August 2013

Published online in Wiley Online Library (wileyonlinelibrary.com). DOI: 10.1002/jbm.b.33034

\begin{abstract}
Various bioactive glass/hydroxyapatite (HA) functional coatings were designed by the suspension plasma spraying (SPS) technique. Their microstructure, scratch resistance, and apatite-forming ability in a simulated body fluid (SBF) were compared. The functional coatings design included: (i) composite coating, that is, randomly distributed constituent phases; (ii) duplex coating with glass top layer onto HA layer; and (iii) graded coating with a gradual changing composition starting from pure $\mathrm{HA}$ at the interface with the metal substrate up to pure glass on the surface. The SPS was a suitable coating technique to produce all the
\end{abstract}

coating designs. The SBF tests revealed that the presence of a pure glass layer on the working surface significantly improved the reactivity of the duplex and graded coatings, but the duplex coating suffered a relatively low scratch resistance because of residual stresses. The graded coating therefore provided the best compromise between mechanical reliability and apatite-forming ability in SBF. (c) 2013 Wiley Periodicals, Inc. J Biomed Mater Res Part B: Appl Biomater 00B: 000-000, 2013.

Key Words: bioactive glass, calcium phosphate(s), in vitro

How to cite this article: Cattini A, Bellucci D, Sola A, Pawłowski L, Cannillo V. 2013. Microstructural design of functionally graded coatings composed of suspension plasma sprayed hydroxyapatite and bioactive glass. J Biomed Mater Res Part B 2013:00B:000-000.

\section{INTRODUCTION}

Calcium phosphates in general and, in particular, hydroxyapatite $\left(\mathrm{HA} ; \mathrm{Ca}_{10}\left(\mathrm{PO}_{4}\right)_{6}(\mathrm{OH})_{2}\right)$ are good biomaterials for orthopedic prostheses because of their similarity to the mineral component of bone, which is a mixture of various salts, such as carbonated apatite, calcium-deficient apatite and whitlockite, and numerous impurities such as sodium, potassium, magnesium, fluoride, and chloride. ${ }^{1}$ As HA is brittle, it is unsuitable for structural applications. Accordingly, the implants for bone repair usually include a HA coating on a metal substrate, which provides the required mechanical strength. ${ }^{2}$ Unfortunately, there are some drawbacks in this design. The most important of them is the fact that crystalline HA is more stable than other calcium phosphates in aqueous media for $\mathrm{pH}$ values between 4.2 and 8.0. This implies that $\mathrm{HA}$ is relatively insoluble at neutral $\mathrm{pH}$ and therefore it reacts so slowly in the human body that it may touch a limit of applicability in specific clinical applications. $^{3}$ However, several results in the literature indicate that the reaction rate of HA coatings is deeply conditioned by their porosity, defectiveness, and degree of crystallinity. ${ }^{4,5}$ Finally, from a technological point of view, the deposition of HA-based coatings is still a challenging issue, despite the progress achieved in several coating deposition meth- ods, especially in thermal spraying. ${ }^{6}$ The main concern is represented by the thermal decomposition of HA, which results in the uncontrolled development of secondary phases, such as tricalcium phosphate (TCP), tetracalcium phosphate (TTCP), and amorphous calcium phosphate (ACP), whose reactivity is hard to predict. Some decomposition phases, such as $\mathrm{CaO}$, may reveal unsuitable for prostheses. $^{7,8}$

As a possible alternative to calcium phosphates, bioactive glasses may be successfully used to coat prosthetic devices. The bone-bonding ability was first detected for specific glasses belonging to the $\mathrm{Na}_{2} \mathrm{O}-\mathrm{CaO}-\mathrm{SiO}_{2}-\mathrm{P}_{2} \mathrm{O}_{5}$ system, with appropriate proportions between the constituent oxides. ${ }^{9}$ Among them, the Bioglass ${ }^{\circledR} 45 \mathrm{~S} 5$ (24.5 wt \% $\mathrm{Na}_{2} \mathrm{O}, 24.5$ wt \% CaO, 6 wt $\% \mathrm{P}_{2} \mathrm{O}_{5}, 45$ wt $\% \mathrm{SiO}_{2}$ ), formulated by Prof. $\mathrm{L}$. $\mathrm{L}$. Hench at the end of the 1960 s, is currently considered to be the reference standard. ${ }^{10}$ Bioactive glasses offer several advantages because they possess the highest degree of bioactivity and their reaction rate may be controlled by their composition. ${ }^{11}$ Particular formulations are even able to interact with soft tissues. ${ }^{12}$ Moreover, bioactive glasses do not decompose at high temperature. However, it is worth noting that the coating deposition by thermal spraying implies the achievement of extremely high temperatures, 


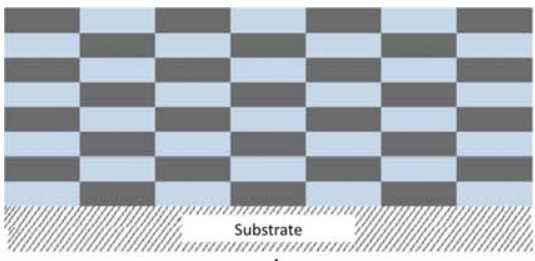

a)

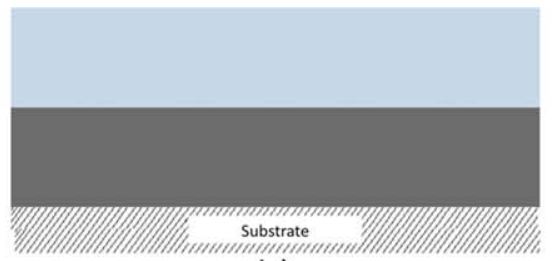

b)

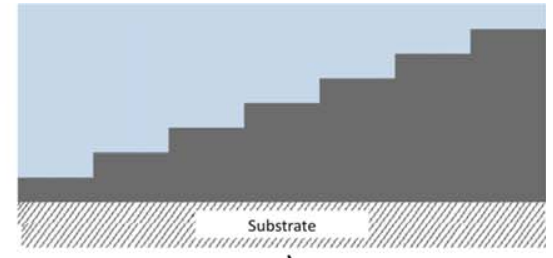

c)

FIGURE 1. Designed microstructures of the biphasic coatings: (a) composite, (b) duplex, and (c) graded. Light blue: BG_Ca glass; Dark grey: HA. [Color figure can be viewed in the online issue, which is available at wileyonlinelibrary.com.]

and bioglasses are prone to devitrification and some of their components may evaporate. ${ }^{13,14}$ The development of crystalline phases is known to alter and retard the bone-bonding ability of the original glass. ${ }^{15,16}$ As a consequence, the introduction of bioactive glass coatings may represent an improvement with respect to conventional systems, but a careful setting of the spraying parameters is required.

In a previous contribution, ${ }^{17}$ the effectiveness of a thin glass topcoat was evaluated to promote the performance of a standard plasma-sprayed HA coating. The glass topcoat was produced by means of the suspension plasma spraying (SPS) technique, a new deposition process which works on suspensions instead of dry powders, thus making it possible to handle even fine particles. ${ }^{18}$

The specific aim of the current study was to produce various glass/HA coatings configurations, and then to verify the effect of the phase distribution on the final properties, especially on the apatite-forming ability in a simulated body fluid (SBF). ${ }^{19}$ The so-called BG_Ca was selected as the bioactive glass (in wt \%: $4.7 \mathrm{Na}_{2} \mathrm{O}, 42.3 \mathrm{CaO}, 6 \mathrm{P}_{2} \mathrm{O}_{5}, 47 \mathrm{SiO}_{2}$ ) because it offers both good bioactivity and a limited tendency to crystallize at high temperature. This is due to its formulation, which is relatively rich in $\mathrm{CaO}$ and poor in $\mathrm{Na}_{2} \mathrm{O}$ with respect to conventional bioactive glasses based on the standard bioglass family. ${ }^{20,21}$

Figure 1 shows three different types of coating designs that were produced and compared in this study. The composite coatings were obtained by spraying a mixture of the two raw materials and therefore the constituent phases were randomly distributed throughout the coating. The duplex coatings consisted of a double-layered structure: BG_Ca on the surface and HA in contact with the substrate. Finally, the graded coatings included both components varying gradually from pure $\mathrm{HA}$ to pure BG_Ca. The latter resulted from the subsequent deposition of many layers with progressively different compositions. Because the volume fraction of each constituent was the same in the three types of coatings, the study was specifically focused on the effect of the phase distribution on the coating behavior.

\section{MATERIALS AND METHODS}

\section{Feedstock materials}

Following the procedure defined in previous articles specifically addressed to the production and deposition of bioactive glass coatings by SPS, the BG_Ca glass was obtained by the conventional melt-quenching method, then it was dry milled in an agate jar, and, to conclude, attrition-milled in ethanol with 2 wt \% of Beycostat C213. ${ }^{20-22}$ The obtained BG_Ca powder had a mono-modal distribution with a mean diameter of $d_{50}=4.7 \mu \mathrm{m}$, as determined with a Partica LA950V2 (Horiba) granulometer. The feedstock suspension was formulated by dispersing $20 \mathrm{wt} \%$ of solid phase in 80 wt \% of ethanol. Ethanol was chosen as the milling and suspending medium because bioactive glasses are waterreactive. $^{23}$

The HA initial powder was a commercial product by Tomita (Japan) and had the mean diameter of $d_{50}=120$ $\mu \mathrm{m}$. The commercial powder was attrition-milled using 0.8 $\mathrm{mm}$ zirconia balls and adding the dispersant Beycostat C213 (2 wt \% of the dry powder). The final powder had a slightly bimodal distribution with a mean diameter of $d_{50}=$ $4.6 \mu \mathrm{m}$ (mean peak at $4.8 \mu \mathrm{m}$, secondary peak at $0.2 \mu \mathrm{m}$ ). The feedstock suspension was formulated by dispersing 20 wt. \% of solid phase in 40 wt \% of ethanol and 40 wt \% of water. The mixture of water and ethanol was chosen instead of pure ethanol (as previously described for the glass powder suspension) because it is known from the literature that water vapor may prevent or slow down the thermal decomposition of HA during plasma spraying. ${ }^{24}$ In particular, because it was necessary to co-spray the HA powder and the BG_Ca one to obtain HA-glass composite layers, the processing conditions had to be chosen in an optimal way for each of the constituent material. ${ }^{22,25}$ Generally speaking, the deposition of the BG_Ca glass requires more power input in the plasma jet than that of HA, so the high power applied to obtain HA-glass biphasic systems was expected to promote the decomposition of HA. Therefore, the addition of water, which is known to cool down the plasma, ${ }^{26}$ aimed to preserve the structure of HA. On the other hand, it is worth noting that, if the HA powder were dispersed in pure water, the enthalpy of the plasma would be reduced to such an extent that the glass particles could not be properly melted anymore. Consequently, the use of an ethanol-water mixture appeared to be the best compromise solution to deal with HA and glass powders at the same time.

\section{Coatings deposition}

TheSG-100 torch (Praxair, S.T., Indianapolis, IN) was used to produce the coatings. The two feedstock suspensions were separately supplied by means of peristaltic pumps described elsewhere. ${ }^{27}$ In addition, two nonreturn valves were mounted to avoid any undesired mixing and reflux phenomena. During 
TABLE I. Spray Parameters

\begin{tabular}{lc}
\hline Parameter & Value \\
\hline Electric power input & $34 \mathrm{~kW}$ \\
Gases & \\
$\mathrm{Ar}$ & $45 \mathrm{slpm}$ \\
$\mathrm{H}_{2}$ & $7.5 \mathrm{slpm}$ \\
Spray distance & $55 \mathrm{~mm}$ \\
Torch speed & $750 \mathrm{~mm} / \mathrm{s}$ \\
Scan step & $10 \mathrm{~mm}$ \\
\hline
\end{tabular}

spraying, the suspensions were continuously stirred to prevent sedimentation and agglomeration. Because the pumping systems were independent, the suspensions mixed together only at the entrance of the injector (for biphasic glass/HA layers only). An injector with a diameter of $500 \mu \mathrm{m}$ was used. This injection of the suspension was internal to the torch at $16 \mathrm{~mm}$ from its exit.

Numerous tests were made to find the optimal deposition parameters that could combine a minimal decomposition of HA with a good cohesion of the BG_Ca particles. The final spray parameters are listed in Table I.

All the coatings were obtained through eight spraying runs, each of which corresponded to four torch passages. Before each session, the sample surface was left to cool down to the temperature below $80^{\circ} \mathrm{C}$.

To obtain the different microstructures of the composite, duplex, and graded coatings, the feed rates of the two suspensions were properly regulated by means of the peristaltic pumps. The values are listed in Table II. The planned compositions are schematically shown in Figure 1.

Substrates were $316 \mathrm{~L}$ stainless steel discs $(25 \mathrm{~mm}$ in diameter, thickness of $8 \mathrm{~mm}$ ). They were sandblasted using corundum powder having a size of $250 \mu \mathrm{m}$ at the pressure of 5 bar. The resulting roughness was $R \mathrm{a}=3.5 \mu \mathrm{m}$. Before spraying, the substrates were ultrasonically washed with ethanol and acetone.

During the deposition, an optical IN 5 Plus pyrometer (Impac) was used to record the surface temperature. The mean values of the temperature were calculated for each spray run, and they are reported in Table III.

The coatings of pure BG_Ca and of pure HA were sprayed using the same parameters applied for the biphasic systems. These coatings were considered as the references.

TABLE II. Suspensions Flow Rates in Different Spray Runs (g/min)

\begin{tabular}{|c|c|c|c|c|c|c|}
\hline \multirow[b]{2}{*}{ Run } & \multicolumn{2}{|c|}{ Composite } & \multicolumn{2}{|c|}{ Duplex } & \multicolumn{2}{|c|}{ Graded } \\
\hline & BG_Ca & $H A$ & BG_Ca & $H A$ & BG_Ca & $H A$ \\
\hline 1 & 15 & 15 & - & 30 & - & 30 \\
\hline 2 & 15 & 15 & - & 30 & 4 & 26 \\
\hline 3 & 15 & 15 & - & 30 & 9 & 21 \\
\hline 4 & 15 & 15 & - & 30 & 13 & 17 \\
\hline 5 & 15 & 15 & 30 & - & 17 & 13 \\
\hline 6 & 15 & 15 & 30 & - & 21 & 9 \\
\hline 7 & 15 & 15 & 30 & - & 26 & 4 \\
\hline 8 & 15 & 15 & 30 & - & 30 & - \\
\hline
\end{tabular}

TABLE III. Surface Temperature (Mean Value and Standard Deviation) Measured During Spraying

\begin{tabular}{lc}
\hline Temperature $\left({ }^{\circ} \mathrm{C}\right)$ & \\
\hline $321 \pm 10$ & Composite \\
$247 \pm 53$ & Duplex \\
$297 \pm 46$ & Graded \\
\hline
\end{tabular}

\section{In vitro tests}

The samples were tested in vitro by soaking them in an SBF solution. ${ }^{19}$ According to the standard protocol defined by Kokubo and Takadama, the SBF volume-to-coating surface ratio has to be $20 \mathrm{~mL} / \mathrm{cm}^{2}{ }^{19}$ Therefore, the samples were cut to obtain a surface area of $1 \mathrm{~cm}^{2}$, and each sample was immersed in $20 \mathrm{~mL}$ of SBF. The samples were removed from the SBF after time periods of 1,7 , and 14 days. During the tests, the SBF was refreshed every 2 days to simulate the dynamic conditions of the human body. The temperature was maintained constant at $37^{\circ} \mathrm{C}$ and the sealed containers were kept in a water-vapor saturated environment to avoid any undesired fluid evaporation. Once extracted from the SBF, the samples were carefully washed with distilled water and dried at room temperature.

\section{Characterization}

The samples were analyzed before and after soaking in SBF using different techniques. The surface of the coatings was investigated by means of X-ray diffraction (XRD). The instrument was an X'pert PRO diffractometer (PANalytical, Almelo, The Netherlands) equipped with an $\mathrm{X}^{\prime}$ Celerator detector. The diffraction patterns were collected in the $10^{\circ}-70^{\circ} 2 \theta$ range (step size: $0.017^{\circ}$, step time: $71.12 \mathrm{~s}$ ).

The microstructural analysis was performed on the coatings' surface and polished cross-section by means of an environmental scanning electron microscope (ESEM; ESEM Quanta 200-FEI Company, Eindhoven, The Netherlands), equipped with an X-EDS microanalysis system (Inca, Oxford Instruments, UK). The microscope was operated in high vacuum (pressure: $10^{-5} \mathrm{~Pa}$ ) and in low-vacuum mode (pressure: $60 \mathrm{~Pa}$ ) according to the specific sample to analyze.

Scratch tests were performed on the surface of the asproduced biphasic coatings (Open platform, CSM Instruments, equipped with $100 \mu \mathrm{m}$ Rockwell diamond tip). The applied load was linearly increased from $20 \mathrm{mN}$ to $30 \mathrm{~N}$ over a scratch length of $3 \mathrm{~mm}$, with a loading rate of $10 \mathrm{~N} /$ min. The critical loads were determined by optical analysis. Three scratches were performed on each sample.

\section{RESULTS AND DISCUSSION}

Regardless of their microstructural design, the obtained biphasic coatings were continuous and well-adhering to the substrates. However, the surfaces of the samples, especially the duplex and the graded ones, were rough, as shown in Figure 2. The roughness was mainly due to the presence of semi-spherical structures, which resulted from sintering and swelling phenomena that occurred for the glass particles. In fact, the surfaces of the duplex and graded samples [Figure 

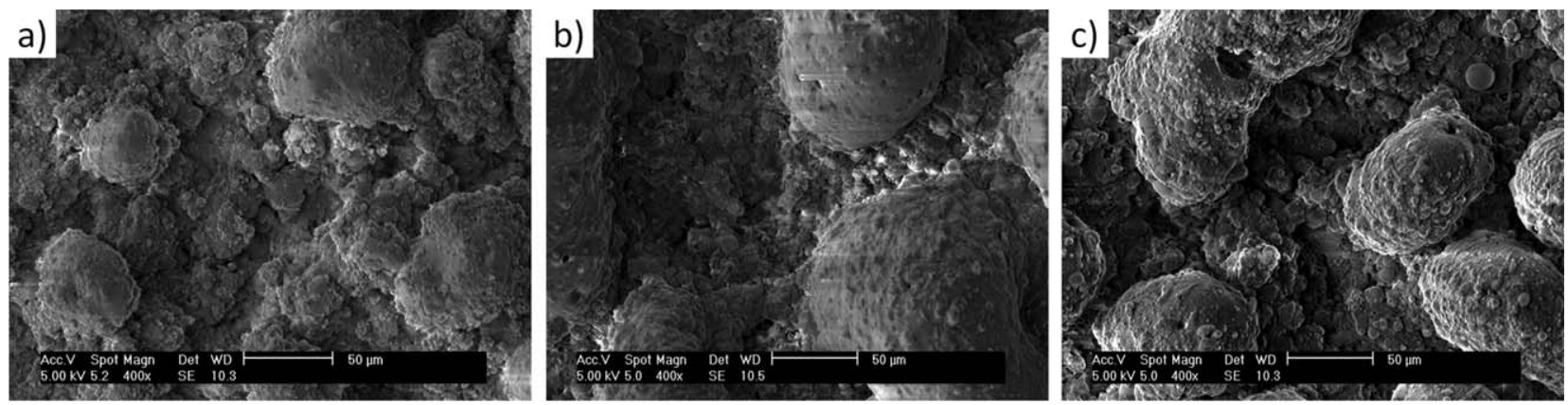

FIGURE 2. ESEM images of the coatings' surface: (a) composite, (b) duplex, and (c) graded.

2(b,c)], which were extremely rich in glass, were similar to that of the pure BG_Ca coating [Figure 3(a)], with a presence of many semi-spherical features. Inversely, the morphology of the composite coating [Figure 2(a)], having a surface rich in HA, was similar to that of the pure HA coating [Figure 3(b)], without any semi-spherical structures. At a higher magnification (Figure 4), both flattened splats and crystallized zones could be observed. The crystals were thin and possessed an acicular morphology. As previously observed for semi-spherical structures, also the
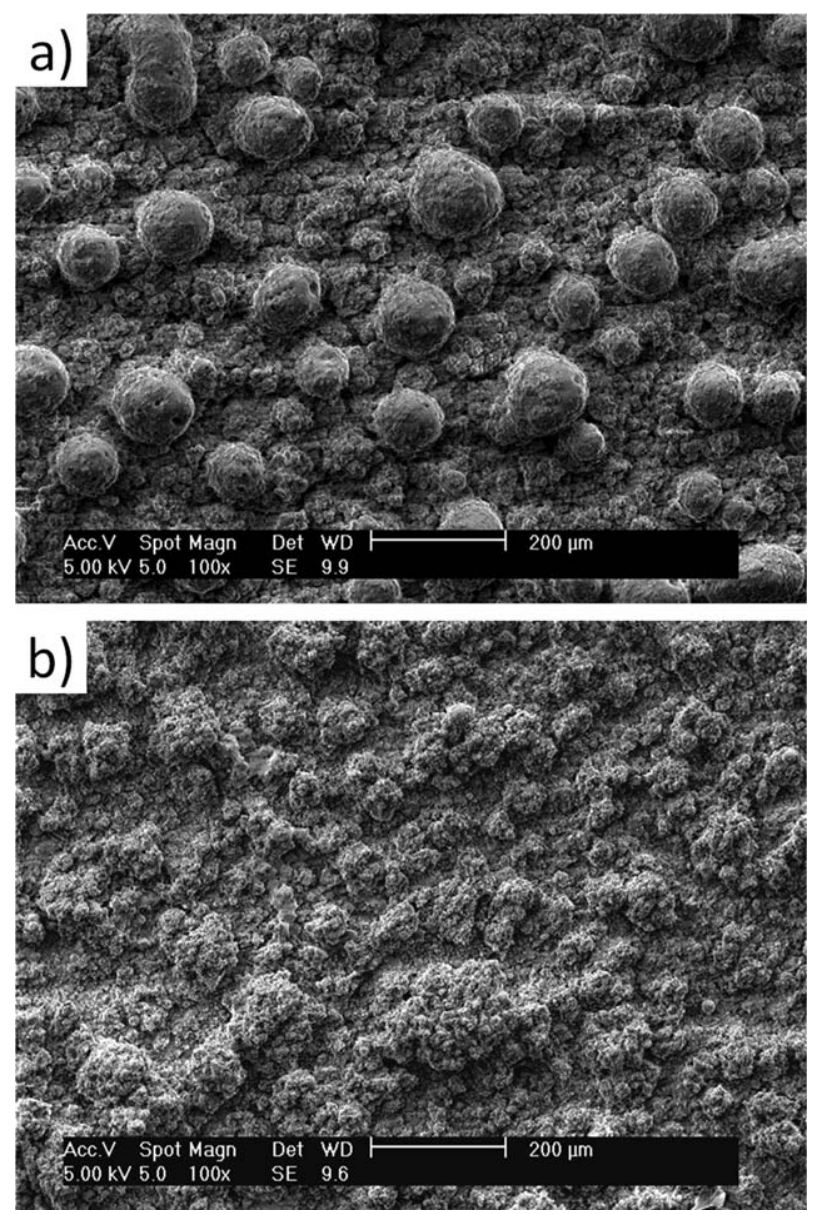

FIGURE 3. ESEM images of the reference coatings' surface: (a) pure BG_Ca and (b) pure HA. crystallizations were more visible in the glass-rich surfaces of the duplex and graded deposits.

To verify whether the obtained microstructures matched the expected ones, the polished cross-sections were observed and analyzed by means of X-EDS analysis. In particular, the compositional maps were acquired to visualize the distribution of silicon, which was selected as the marker of the BG_Ca glass, and that of phosphorus, which was chosen to indicate HA. As shown in Figure 5, a good correspondence could be generally detected. More in detail, the microstructure of the composite sample [Figure 5(a)] presented HA-rich areas dispersed in a glass matrix. The crosssection of the duplex sample [Figure 5(b)] was clearly divided into two layers. Finally, in the graded sample [Figure 5(c)], the composition smoothly changed across the thickness of the coating. However, it was apparent that the relative volume fraction of the glass in the final samples was greater than expected. Most likely, this discrepancy was because of the higher deposition efficiency of the bioactive glass with respect to that of HA. This explanation is confirmed by the comparison between the cross-sections of the mono-component coatings, which is presented in Figure 6 . In fact, the pure BG_Ca coating was twice as thick as the pure HA one, although both of them were produced using the same processing parameters.

The XRD spectra of the coatings are shown in Figure 7. For comparison, Figure 7 incorporates the X-ray spectra of the mono-component coatings. A clear similarity between the patterns of the duplex and the graded samples can be easily observed. They are also similar to the spectrum of the pure BG_Ca coating. In the spectra, the broadband between $25^{\circ}$ and $35^{\circ}(2 \theta)$ was due to the amorphous glassy phase, because it is typical of silicate glasses, ${ }^{28}$ and the peaks of pseudowollastonite $\left(\mathrm{CaSiO}_{3}\right)$ could be detected as a result of a limited devitrification of the original glass. Instead, the pattern of the composite sample was more similar to that of the pure HA coating. This is not surprising because, in this sample, a high amount of HA was present on the surface. In the spectrum of the composite coating, the peaks of HA and the band of glass were both present, but the development of pseudowollastonite was not evident. It is worth noting that the diffraction pattern of the pure HA coating, besides the peaks of the HA itself, showed some secondary peaks attributable to the decomposition phases 

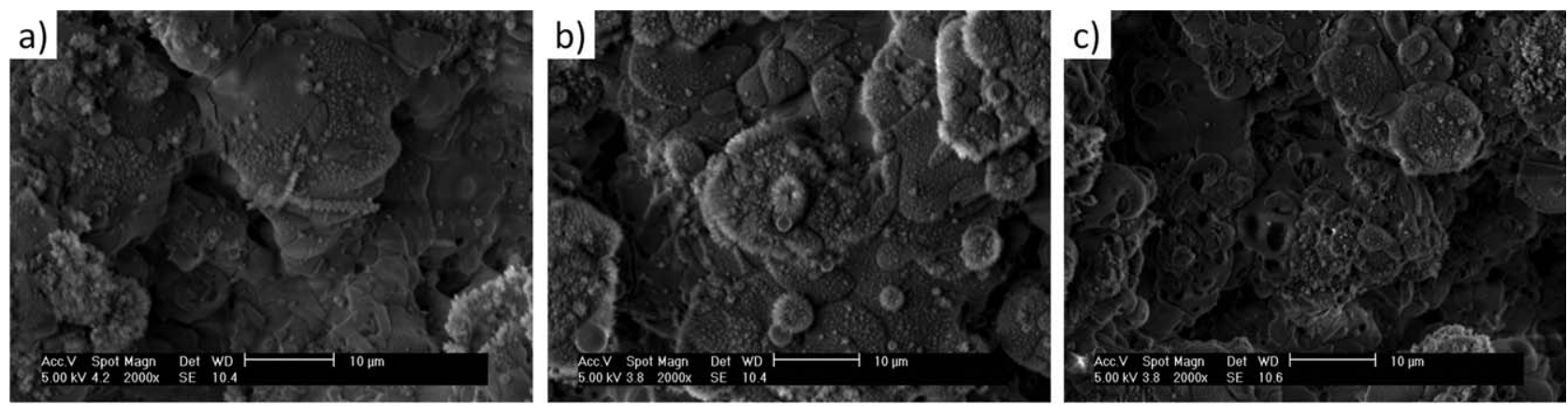

FIGURE 4. High-magnification ESEM images of the coatings' surface: (a) composite, (b) duplex, and (c) graded.

such as TTCP, TCP, and CaO. Because the composite, duplex, and graded coatings were sprayed using the same parameters as the pure HA one, it is probable that also the HA present in biphasic coatings could have decomposed, even if the peaks of the secondary phases were not visible because of the presence of the bioactive glass, which surrounded (in the composite coating) or covered (in the duplex and graded coatings) the HA grains.

The mechanical characterization of the samples was made using the scratch test. The critical load was defined as the load at which the metal substrate became detectable. The critical load values were mainly determined by means of optical observation, but also frictional force and acoustic emission were useful for its detection (Figure 8). The critical load (mean value \pm standard deviation) was $27.1 \pm 0.8 \mathrm{~N}$ for the composite coating and $21.2 \pm 1.7 \mathrm{~N}$ for the duplex one. During the scratch test of the graded sample, the maximum applied load (30 N) was not enough to reach the substrate. Therefore, the graded microstructure provided the best scratch resistance. Probably, the double-layered structure of the duplex sample, with an abrupt interface between the glass and the HA, promoted the generation of residual stresses. The stresses could have been strongly reduced by the progressive change in composition of the graded coating. ${ }^{29}$

With regards to the in vitro tests, the SEM analysis revealed that, already after 1 day of immersion in SBF, the surface morphology of the biphasic samples changed; indeed, diffused "cauliflower-like" features could be detected [Figure $9(\mathrm{a}-\mathrm{c})]$, which are characteristic of the hydroxycarbonate-apatite deposits grown in vitro. ${ }^{30,31}$ All the biphasic samples followed a similar evolution. Instead, if the mono-component coatings are considered, the surface of the BG_Ca sample showed the same behavior of the biphasic coatings, with the development of dome-like features [Figure $10(\mathrm{a})]$, whereas the apatite-forming ability of the pure HA coating was less visible. In fact, as shown in Figure 10 (b), the surface of the HA coating did not undergo any significant change as a result of the immersion in SBF.

Further details on the in vitro behavior could be deduced by the analysis of the polished cross-sections, which are presented in Figures 11-13. Generally speaking, the duplex and the graded coatings evolved in a similar way and they both reproduced the transformations occurring on the pure BG_Ca coating; the composite sample, instead, was slightly different because HA particles were dispersed throughout the coating thickness, thus a layered microstructure was not recognizable. Finally, the pure HA coating remained almost unaltered by the SBF.

After 1 day of immersion, the cross-sections of the duplex [Figure 11(a)] and graded [Figure 12(a)] samples showed a layered structure. Both samples had a surface layer rich in calcium and phosphorus, and a deeper layer mainly composed of silicon; below them, the deepest part of the coating was still unchanged. On account of the data available in the literature, it is possible to conclude that the
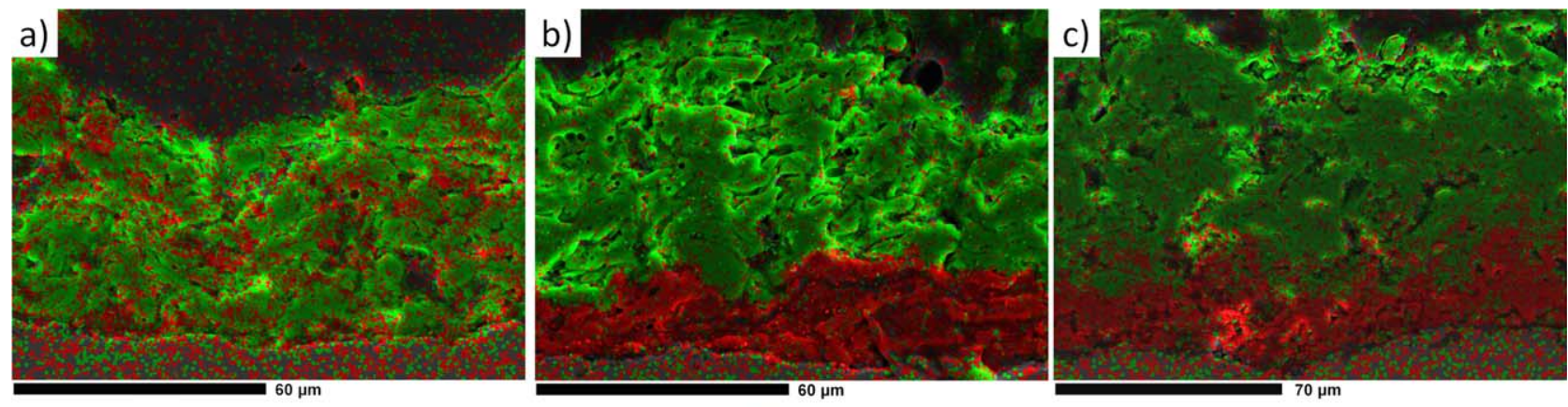

- Si $\square \mathrm{P}$

FIGURE 5. X-EDS maps showing the distribution of $\mathrm{Si}$ (in green - representative of the BG_Ca glass) and $\mathrm{P}$ (in red - representative of HA) on the cross-sections: (a) composite, (b) duplex, and (c) graded. [Color figure can be viewed in the online issue, which is available at wileyonlinelibrary.com.] 


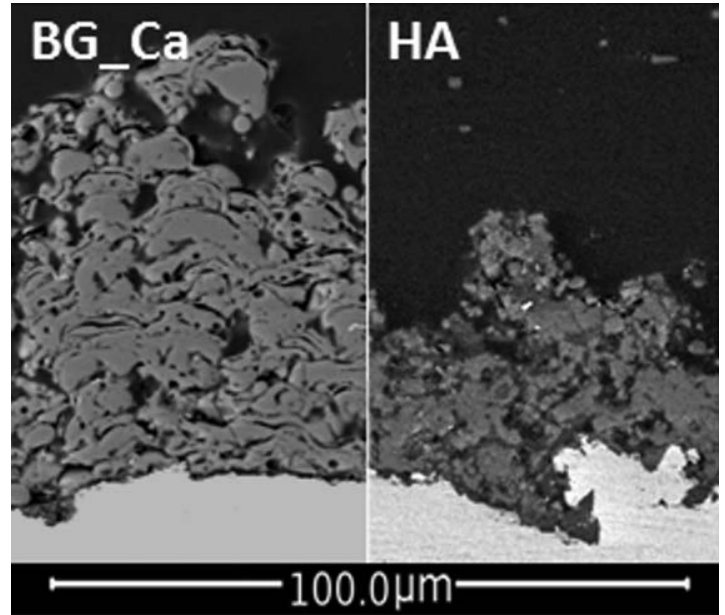

FIGURE 6. ESEM images of the reference coatings' cross-sections.

surface layer was the result of the precipitation and growth of HA induced by the reaction between the glass and the SBF, mediated by the development of a silica gel layer. ${ }^{32,33}$ As previously mentioned, the same behavior was observed on the cross-section of the BG_Ca coating, which displayed a HArich layer on the surface and a silica gel zone underneath. In this sample, the silica gel layer grew quickly, such that the coating was almost completely converted to silica gel already after 1 week of immersion in SBF (data not shown).

In addition, the composite coating [Figure 13(a)] was able to promote the development of a thin reaction deposit, which was rich in $\mathrm{Ca}$ and $\mathrm{P}$. Moreover, localized silica gel zones and unreacted glass areas could be detected. Nevertheless, in this case, there was not a clearly stratified structure, but only the single spots dispersed throughout the coating thickness. This was due to the initial microstructure

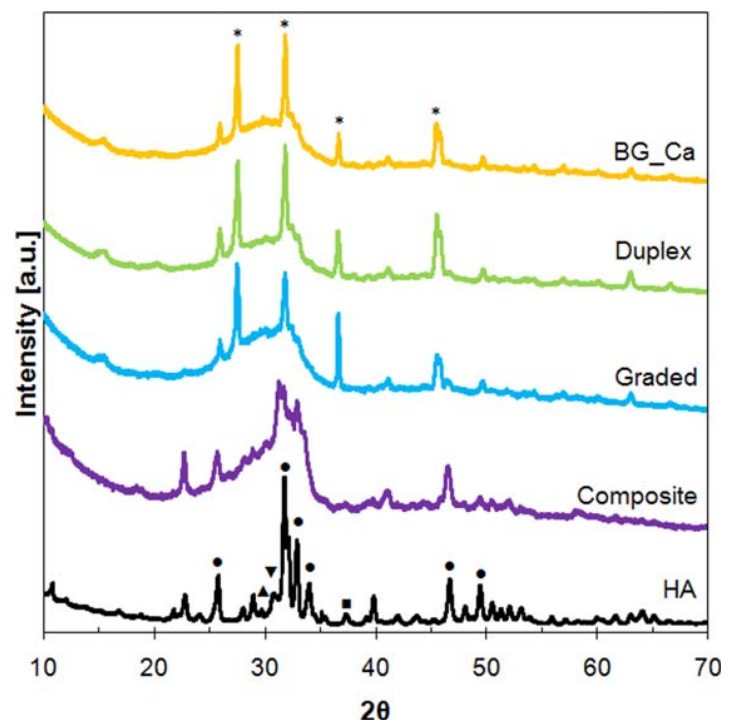

FIGURE 7. X-ray diffraction patterns of the as-produced coatings *: pseudowollastonite [01-089-6485], $\mathbf{\Delta}$ : TTCP [00-025-1137], $\boldsymbol{\nabla}:$ TCP [00009-0169], घ: $\mathrm{CaO}$ [01-075-0264], : HA [01-089-6437]. [Color figure can be viewed in the online issue, which is available at wileyonlinelibrary.com.]

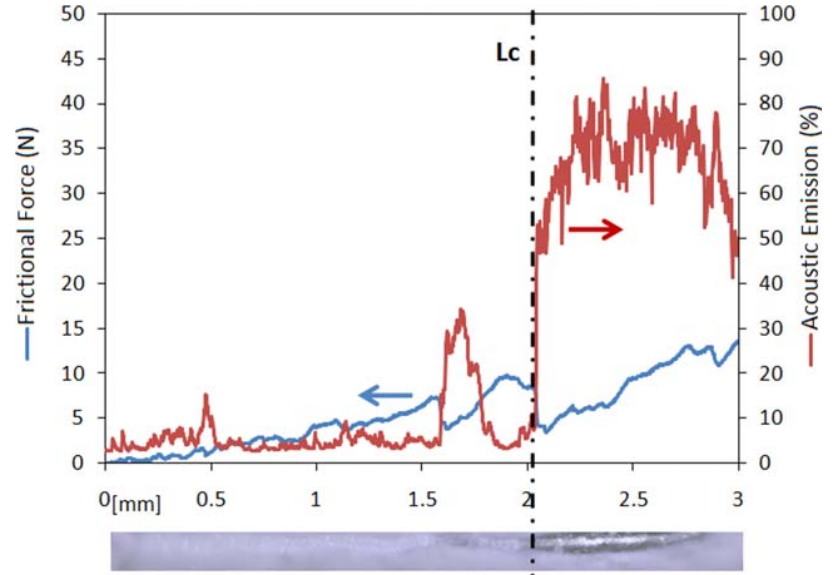

FIGURE 8. Analysis of a representative scratch test (duplex coating): juxtaposition of acoustic emission graph, frictional force graph, and optical analysis. [Color figure can be viewed in the online issue, which is available at wileyonlinelibrary.com.]

of the composite coating in which areas of BG_Ca were interspersed with HA zones. In fact, the reactions in SBF primarily involved the BG_Ca particles that could be reached by the SBF percolating through the residual pores and possible cracks present in the coating, whereas the HA-rich zones remained almost unchanged. As previously mentioned, the limited apatite-forming ability of the HA phase is even more evident if the pure HA coating is considered. In fact, the areas with different $\mathrm{Ca} / \mathrm{P}$ ratios could be observed on the cross-section only after 1 week in SBF (these data are not shown). In particular, a Ca-deficient layer was detected on the surface, which may correspond to the development of a Ca-poor ACP, as described by Kim et al. ${ }^{34}$ After 2 weeks in $\mathrm{SBF}$, the duplex [Figure 11(b)] and graded [Figure 12(b)] samples had an unusual microstructure. In fact, they both showed the highest concentration of silicon in the deepest part of the cross-section, close to the interface with the metal substrate. This behavior is commonly observed in bioactive glasses, ${ }^{33}$ because the reaction with SBF starts at the glass surface and then it moves inward. Accordingly, in bioactive glass coatings, the deepest layers in contact with the substrate are usually the last part of the coating that undergoes chemical changes to silica gel first and then to HA. However, such phenomenon is difficult to explain for the duplex and graded samples, because in the original unreacted coatings, there was no glass at the interface with the substrate, but HA (Figure 5). One possible explanation is that, at the beginning of the reaction process with the $\mathrm{SBF}$, the BG_Ca-rich layers on the surface quickly reacted to form silica gel and HA. In a second step, the reaction proceeded further, involving the underlying HA-rich layers. In this way, the deepest layers of the coatings, consisting of HA, were dissolved by the SBF, and the precipitation of new HA did not take place in the same point, but on the surface of the preexisting silica gel and HA layers (derived from the precocious reaction of the BG_Ca-rich fractions). This involved a gradual migration of the silicon-rich zone downward in the direction of the substrate. 

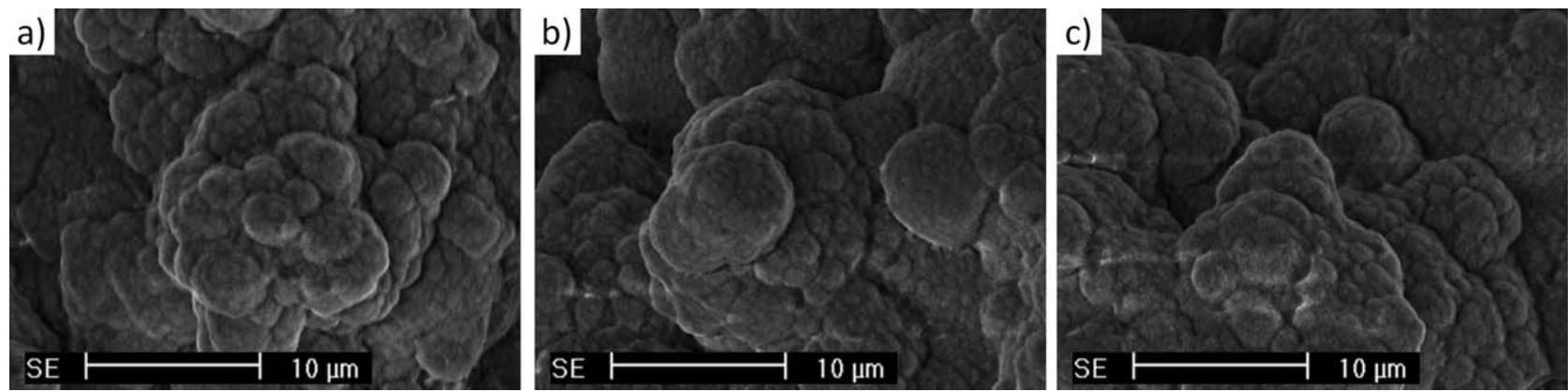

FIGURE 9. SEM images (secondary electrons) of the biphasic coatings' surface after 14 days in SBF: (a) composite, (b) duplex, and (c) graded.

The silicon-rich zone close to substrate was not observed in the composite coating [Figure 13(b)] in which silicon-rich particles were still present throughout the thickness of the coating even after 2 weeks of immersion in SBF. Again, the different behavior of the composite coating depends on both its "zoned" (not layered) microstructure and the different reaction kinetics of bioactive glass and HA in a physiological environment.

The XRD analysis basically confirmed the reaction model previously outlined according to the SEM observations. As far as the composite coating is concerned, the diffraction spectra (Figure 14) should be considered with caution,
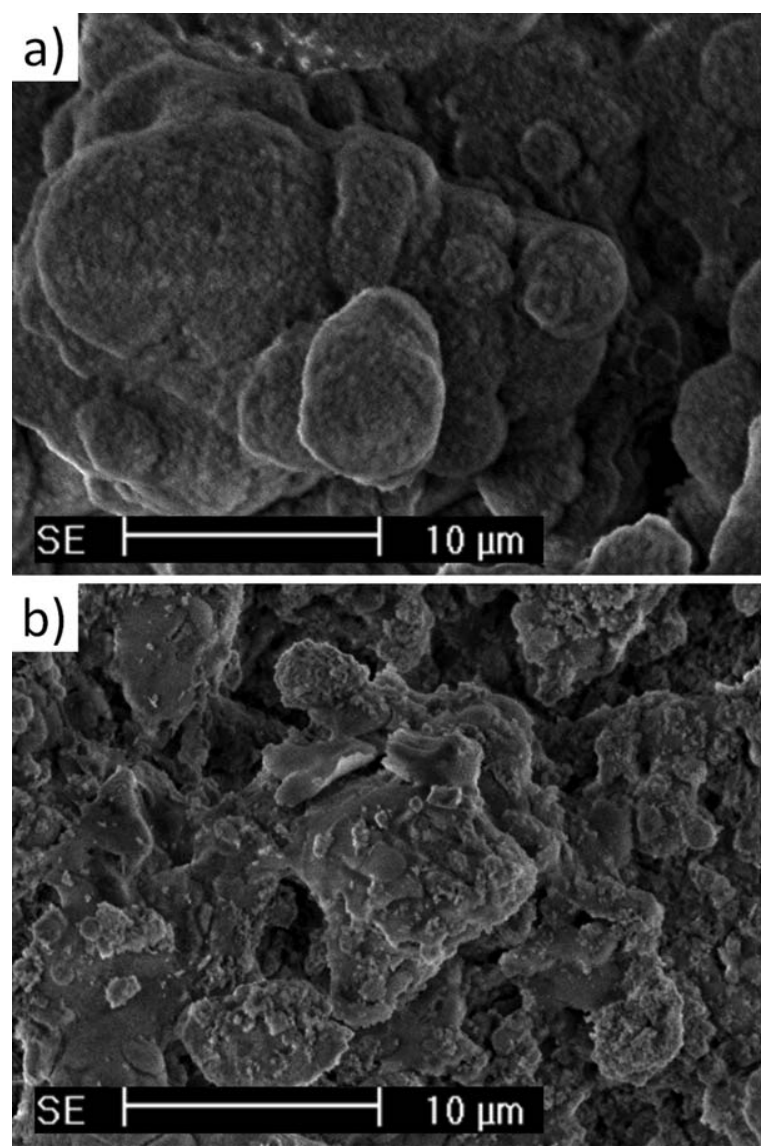

FIGURE 10. SEM images of the reference coatings' surface after 14 days in SBF: (a) BG_Ca and (b) HA. because the HA peaks were already present in the XRD diagram of the as-produced sample, thus confusing the identification of the peaks associated with the in vitro grown HA.
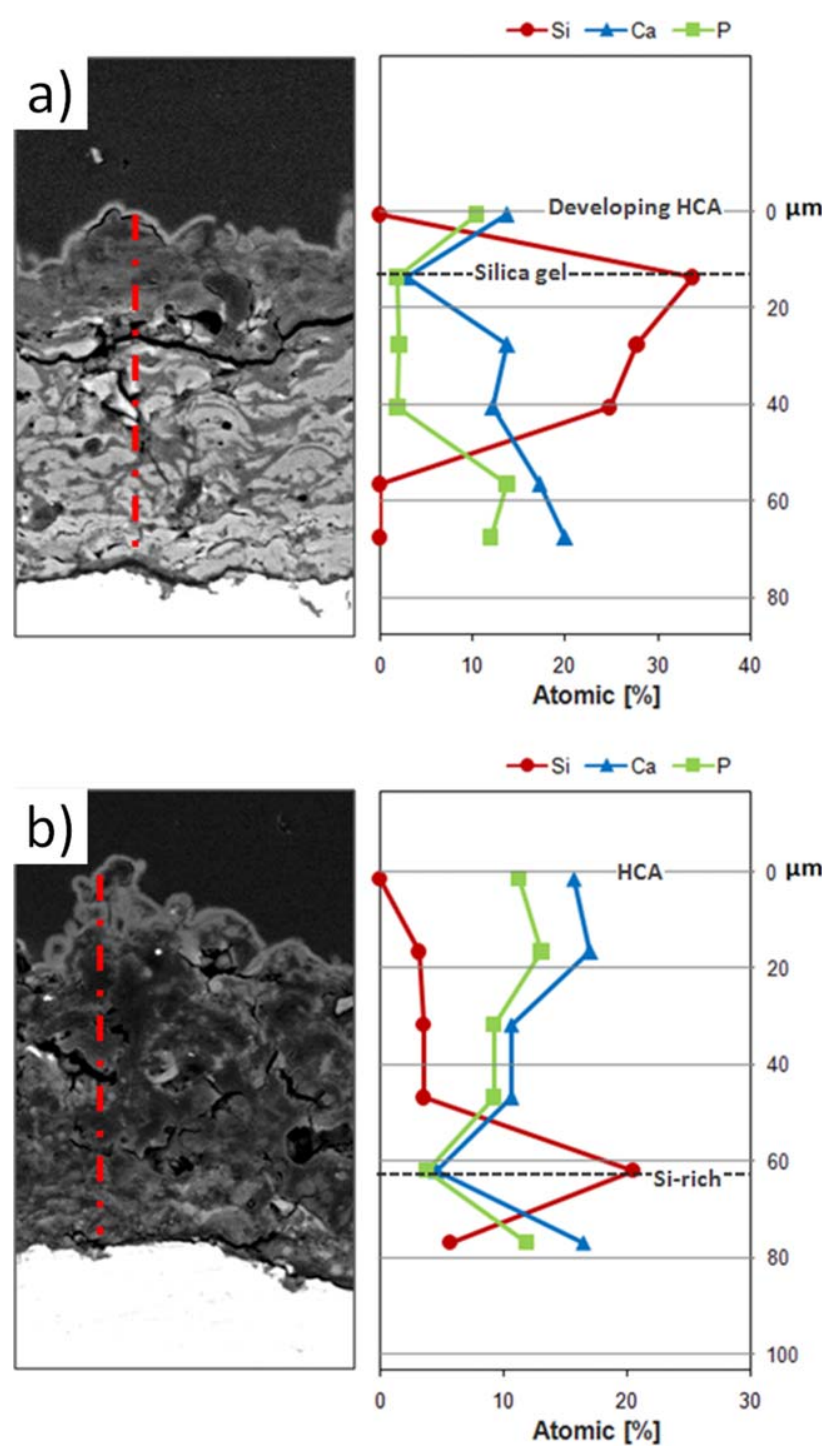

FIGURE 11. Microstructure and X-EDS analysis of the cross-section of the duplex coating after 1 day in SBF (a) and after 14 days in SBF (b). [Color figure can be viewed in the online issue, which is available at wileyonlinelibrary.com.] 

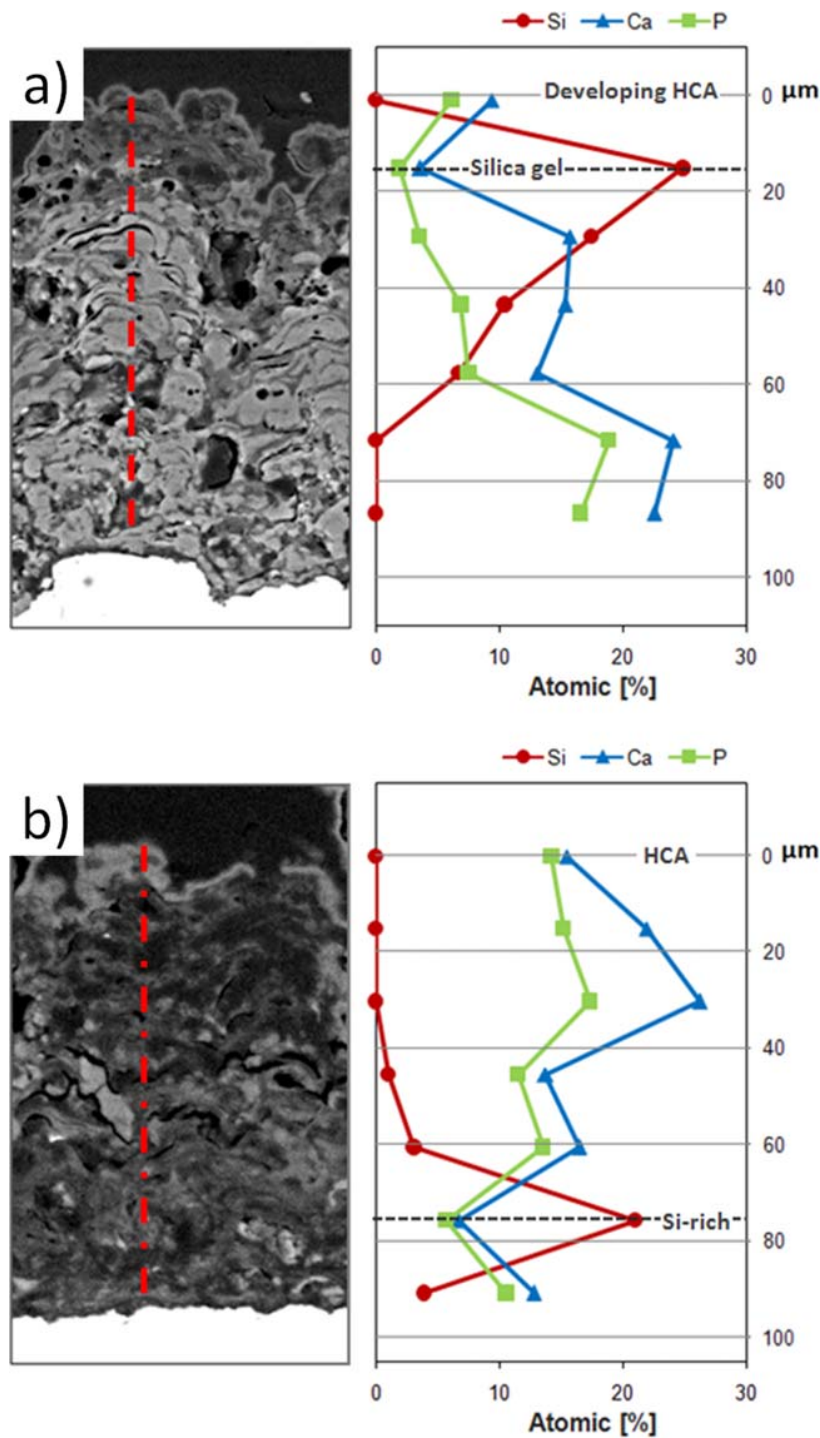

FIGURE 12. Microstructure and X-EDS analysis of the cross-section of the graded coating after 1 day in SBF (a) and after 14 days in SBF (b). [Color figure can be viewed in the online issue, which is available at wileyonlinelibrary.com.]

Nevertheless, it is possible to see a gradual change in the spectra, because the broad halo in the $25^{\circ}-35^{\circ} 2 \theta$ range, reflecting the presence of the BG_Ca (silicate) glass, progressively disappeared as a result of the glass dissolution-HA precipitation process. As already seen for the ESEM images, also comparing the evolution of the XRD spectra after in vitro tests, a similar behavior could be observed for the duplex (Figure 15) and the graded (Figure 16) samples. The peaks associated with the partial crystallization of the glassy phase (pseudowollastonite) completely disappeared after 1 week of immersion; at the same time, the main peaks of HA became visible. A broad halo in the $20^{\circ}-25^{\circ} 2 \theta$ range was due to the growth of a silica gel layer, whereas the peaks of calcium carbonate, coprecipitated with HA, could be observed occasionally. ${ }^{19,35}$ After 2 weeks in SBF, the peaks in the diffraction spectra of the duplex and graded samples were exclusively associated with HA. However, the peaks were still broad, thus confirming the defective and microcrystalline nature of the HCA developed in vitro. ${ }^{36}$

The XRD spectra of the pure BG_Ca coating showed the same trend (data not shown). However, in this case, after 2 weeks of immersion, the silica gel was still detectable and the peaks of the precipitated HA looked even broader than in the duplex and graded spectra. This result suggests that the presence of the HA-rich areas underneath the bioactive glass surface layer did not compromise the reaction kinetics in the duplex and graded coatings.

To conclude, the XRD spectra of the pure HA coating showed a limited change, even if the peaks associated with the secondary phases (such as TTCP, TCP, etc.) gradually disappeared starting from the first day of immersion (data not shown). In fact, it is known from the literature that the solubility of both TTCP and TCP is greater than that of (crystalline) HA. ${ }^{37}$
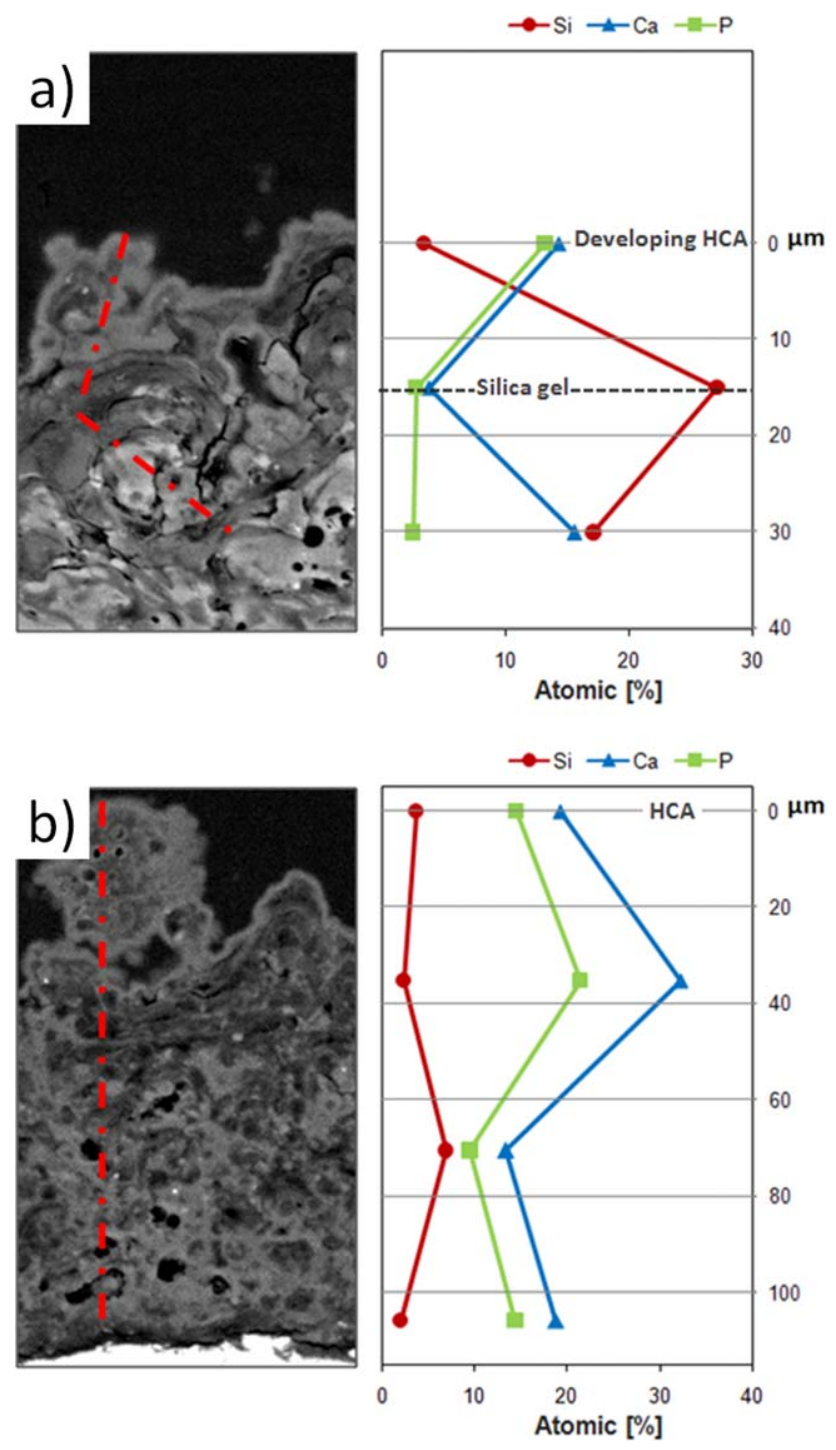

FIGURE 13. Microstructure and X-EDS analysis of the cross-section of the composite coating after 1 day in SBF (a) and after 14 days in SBF (b). [Color figure can be viewed in the online issue, which is available at wileyonlinelibrary.com.] 


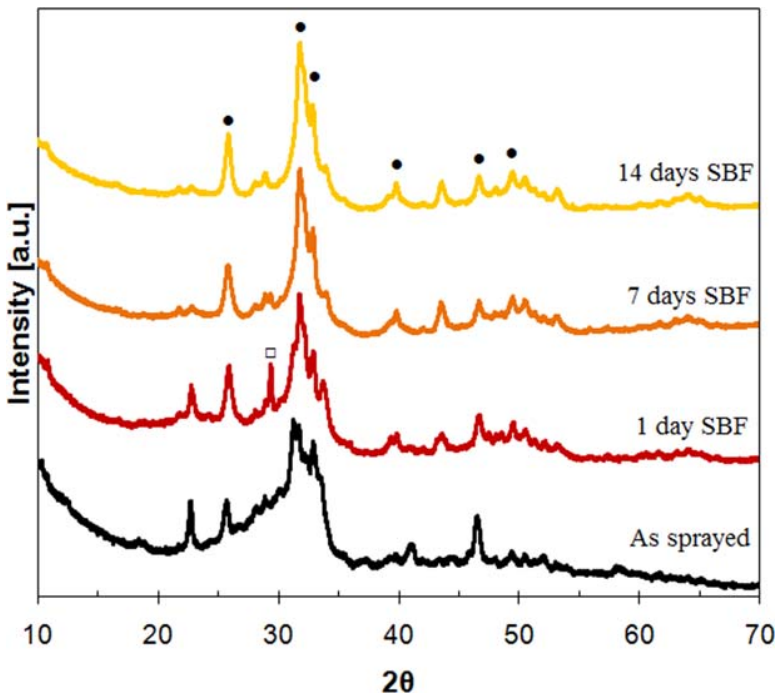

FIGURE 14. XRD of the composite coatings after in vitro tests. $\square$ : $\mathrm{CaCO}_{3}$ [01-085-1108], $\mathrm{O}$ : HA. [Color figure can be viewed in the online issue, which is available at wileyonlinelibrary.com.]

\section{CONCLUSIONS}

In this study, various bioactive glass/HA biphasic coatings were produced by means of SPS. To reveal the importance of the phase distribution, three different layouts were considered: (i) composite coating, that is, randomly distributed constituent phases; (ii) duplex coating with glass top layer onto HA layer; and (iii) graded coating with a gradual changing composition starting from pure HA at the interface with the metal substrate up to pure glass on the surface.

All the biphasic coatings had a good adhesion to the substrate and they were continuous. Moreover, the obtained microstructure met the designed ones, although the glass fraction was greater than the designed one because of the HA deposition efficiency, which was lower than the glass one. However, the deposition technique and the spray setup

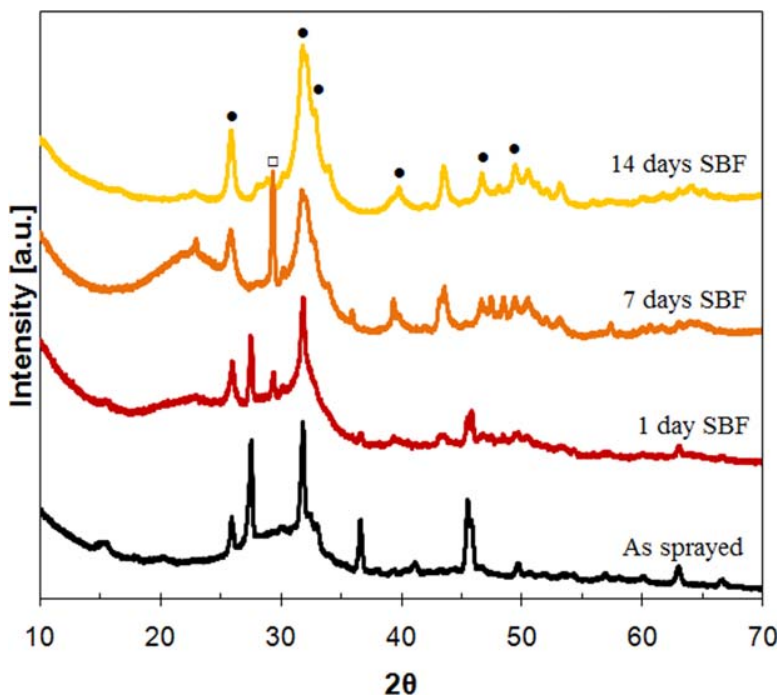

FIGURE 15. XRD of the duplex coatings after in vitro tests. $\square: \mathrm{CaCO}_{3}$ : HA. [Color figure can be viewed in the online issue, which is available at wileyonlinelibrary.com.]

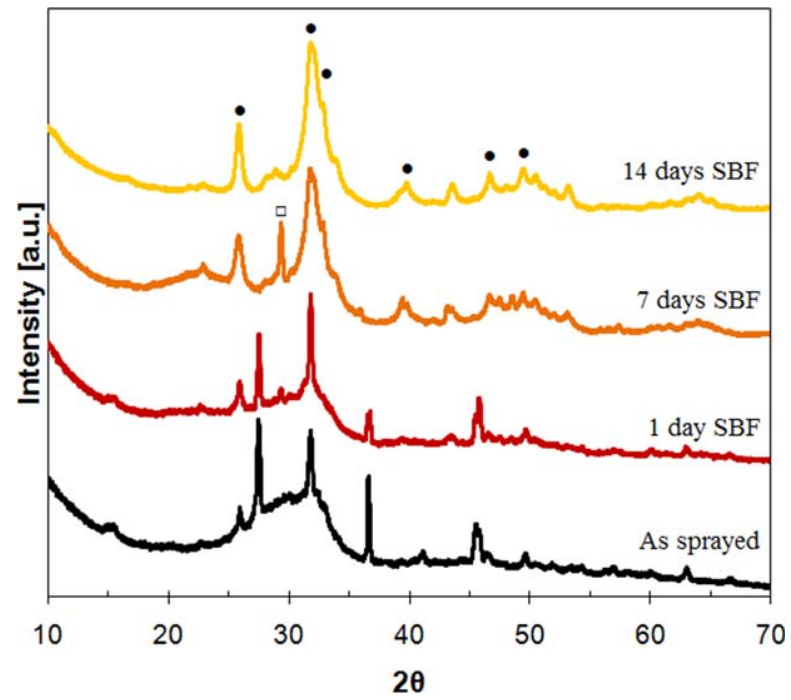

FIGURE 16. XRD of the graded coatings after in vitro tests. $\square: \mathrm{CaCO}_{3}$, : HA. [Color figure can be viewed in the online issue, which is available at wileyonlinelibrary.com.]

proved to be proper for producing coatings with specific microstructures.

According to the in vitro tests, all the coatings were able to promote the development of apatite when immersed in an SBF. Nevertheless, the apatite-forming ability was especially evident for those coatings, which presented a glassrich layer on the surface (i.e., duplex and graded). As regards the mechanical performance, the duplex configuration should be avoided, because the abrupt interface between the glass topcoat and the HA layer implies relevant residual stresses, which undermine the scratch resistance.

The graded coating therefore seems to be the most promising solution, because it combines a good apatiteforming ability and a strong adhesion to the substrate, as observed by means of scratch tests.

\section{ACKNOWLEDGMENTS}

The Vinci Program (Italian-French University) support for Dr. A. Cattini is gratefully acknowledged.

\section{REFERENCES}

1. de Groot K, Wolke JGC, Jansen JA. Calcium phosphate coatings for medical implants. Proc Inst Mech Eng H 1998;212:137-147.

2. Chevalier J, Gremillard L. Ceramics for medical applications: A picture for the next 20 years. J Eur Ceram Soc 2009;29:1245-1255.

3. Juhasz JA, Best SM. Bioactive ceramics: Processing, structures and properties. J Mater Sci 2012;47:610-624.

4. Sun L, Berndt CC, Gross KA, Kucuk A. Material fundamentals and clinical performance of plasma-sprayed hydroxyapatite coatings: A review. J Biomed Mater Res 2001;58:570-592.

5. Stiegler N, Bellucci D, Bolelli G, Cannillo V, Gadow R, Killinger A, Lusvarghi L, Sola A. High-velocity suspension flame sprayed (HVSFS) hydroxyapatite coatings for biomedical applications. J Ther Spray Techn 2012;21:275-287.

6. Cheang $P$, Khor KA. Addressing processing problems associated with plasma spraying of hydroxyapatite coatings. Biomaterials 1996;17:537-544.

7. Liao C-J, Lin F-H, Chen K-S, Sun J-S. Thermal decomposition and reconstitution of hydroxyapatite in air atmosphere. Biomaterials 1999; 20:1807-1813. 
8. Lu Y-P, Song Y-Z, Zhu R-F, Li M-S, Lei T-Q. Factors influencing phase compositions and structure of plasma sprayed hydroxyapatite coatings during heat treatment. Appl Surf Sci 2003;206: 345-354.

9. Hench LL. Bioceramics: From concept to clinic. J Am Ceram Soc 1991;74:1487-1510.

10. Hench LL. The story of Bioglass $\AA$. J Mater Sci-Mater M 2006;17: 967-978.

11. Jones JR. Review of bioactive glass: From Hench to hybrids. Acta Biomater 2013:9:4457-4486.

12. Rahaman MN, Day DE, Sonny Bal B, Fu Q, Jung SB, Bonewald LF, Tomsia AP. Bioactive glass in tissue engineering. Acta Biomater 2011;7:2355-2373.

13. Lefebvre L, Gremillard L, Chevalier J, Zenati R, Bernache-Assolant D. Sintering behaviour of $45 \mathrm{~S} 5$ bioactive glass. Acta Biomater 2008; 4:1894-1903.

14. Bretcanu O, Chatzistavrou $\mathrm{X}$, Paraskevopoulos $\mathrm{K}$, Conradt $\mathrm{R}$ Thompson I, Boccaccini AR. Sintering and crystallisation of $45 \mathrm{~S} 5$ Bioglass ${ }^{\circledR}$ powder. J Am Ceram Soc 2009;29:3299-3306.

15. Boccaccini AR, Chen Q, Lefebvre L, Gremillard L, Chevalier J. Sintering, crystallisation and biodegradation behaviour of Bioglass $®$ derived glass ceramics. Faraday Discuss 2007;136:27-44.

16. Bellucci D, Cannillo V, Sola A. An overview of the effects of thermal processing on bioactive glasses. Sci Sinter 2010; 42:307-320.

17. Cattini A, Bellucci D, Sola A, Pawłowski L, Cannillo V. Functional bioactive glass topcoats on hydroxyapatite coatings: Effects on microstructure and in-vitro bioactivity. Forthcoming.

18. Pawłowski L. Suspension and solution thermal spray coatings. Surf Coat Tech 2009;203:2807-2829.

19. Kokubo T, Takadama $\mathrm{H}$. How useful is SBF in predicting in vivo bone bioactivity? Biomaterials 2006;27:2907-2915.

20. Lockyer MGW, Holland D, Dupree R. NMR investigation of the structure of some bioactive and related glasses. J Non-Cryst Solids 1995;188:207-219.

21. Sola A, Bellucci D, Raucci MG, Zeppetelli S, Ambrosio L, Cannillo V. Heat treatment of Na2O-CaO-P2O5-SiO2 bioactive glasses: Densification processes and postsintering bioactivity. J Biomed Mater Res A 2012;100A:305-322.

22. Cattini A, Łatka L, Bellucci D, Bolelli G, Sola A, Lusvarghi L, Pawłowski L, Cannillo V. Suspension plasma sprayed bioactive glass coatings: Effects of processing on microstructure, mechani- cal properties, and in-vitro behaviour. Surf Coat Tech 2013;220: 52-59.

23. Zeng Y-P, Jiang D-L, Werner J-P, Greil P. Fabrication of Al2O3A/W bioglass bioactivity tapes by tape casting. Mater Lett 2002; 57:463-468.

24. Li H, Khor KA, Cheang P. Effect of steam treatment during plasma spraying on the microstructure of hydroxyapatite splats and coatings. J Ther Spray Techn 2006;15:610-616.

25. Kozerski S, Pawlowski L, Jaworski R, Roudet F, Petit F. Two zones microstructure of suspension plasma sprayed hydroxyapatite coatings. Surf Coat Tech 2010;204:1380-1387.

26. Pateyron B, Calve N, Pawłowski L. Influence of water and ethanol on transport properties of the jets used in suspension plasma spraying. Surf Coat Tech 2013;220:257-260.

27. Tomaszek R, Pawłowski L, Gengembre L, Laureyns J, Le Maguer A. Microstructure of suspension plasma sprayed multilayer coatings of hydroxyapatite and titanium oxide. Surf Coat Tech 2007; 201:7432-7440.

28. Navarro JMF, El Vidrio. Madrid: C.S.I.C.; 1991.

29. Cannillo V, de Portu G, Micele L, Montorsi M, Pezzotti G, Siligardi C, Sola A. Microscale computational simulation and experimental measurement of thermal residual stresses in glass-alumina functionally graded materials. J Am Ceram Soc 2006;26:1411-1419.

30. Li J, Liao H, Sjöström M. Characterization of calcium phosphates precipitated from simulated body fluid of different buffering capacities. Biomaterials 1997;18:743-747.

31. Pattanayak DK. Apatite wollastonite-poly methyl methacrylate bio-composites. Mater Sci Eng C 2009;29:1709-1714.

32. Hench LL. Bioceramics. J Am Ceram Soc 1998;81:1705-1728.

33. Sola A, Bellucci D, Cannillo V, Cattini A. Bioactive glass coatings: A review. Surf Eng 2011;27:560-572.

34. Kim HM, Himeno T, Kokubo T, Nakamura T. Process and kinetics of bonelike apatite formation on sintered hydroxyapatite in a simulated body fluid. Biomaterials 2005;26:4366-4373.

35. Cannillo V, Sola A. Potassium-based composition for a bioactive glass. Ceram Int 2009:35:3389-3393.

36. Vitale Brovarone C, Verné E, Appendino P. Macroporous bioactive glass-ceramic scaffolds for tissue engineering. J Mater Sci-Mater M 2006;17:1069-1078.

37. Dorozhkin SV. Calcium orthophosphates in nature, biology and medicine. Materials 2009;2:399-498. 